\title{
Speech and Linguistic Features of Children With Articulation Disorder
}

\author{
Jiyong Kim, MD' ${ }^{1}$, Seong Woo Kim, $\mathrm{MD}^{2}$, Ha Ra Jeon, $\mathrm{MD}^{2}$, Mee Ryung Woo, $\mathrm{MA}^{3}$, Hyo In Kim, $\mathrm{MD}^{2}$ \\ ${ }^{1}$ Department of Physical Medicine and Rehabilitation, Inje University Ilsanpaik Hospital, Goyang; \\ ${ }^{2}$ Department of Physical Medicine and Rehabilitation, National Health Insurance Service Ilsan Hospital, Goyang; \\ ${ }^{3}$ Rehabilitation Treatment Center, National Health Insurance Service Ilsan Hospital, Goyang, Korea
}

\begin{abstract}
Objective To analyze speech and linguistic features in children with articulation disorder characterized by consonant and vowel phonological errors.

Methods Between February 2007 and June 2015, 117 children who showed articulation disorder were selected for the study. Based on comprehensive speech and language assessments, the subjects were classified into articulation dysfunction (AD), or AD overlapping with language delay. Detailed information of articulation, including percentage of consonants correct (PCC) and normal percentage of variable consonants derived from the Assessment of Phonology and Articulation for Children test, were compared between the two groups.

Results Totally, 55 children were diagnosed as AD and 62 as AD with language delay. Mean PCC was not significantly different between the two groups. In both groups, the acquisition order of consonants followed the universal developmental sequence. However, differences were observed in the nasal \& plosive consonants abnormality between the two groups. When adjusted to their delayed language level in AD with language delay group, 53\% of children had appropriate articulation function for their expressive language level.

Conclusion Speech and linguistic characteristics in children with articulation disorder were variable. Therefore, comprehensive assessment is required in children with inaccurate pronunciation, and a proper treatment plan based on the results of assessment should be followed.
\end{abstract}

Keywords Childhood, Articulation disorders, Developmental language disorders

\section{INTRODUCTION}

Communication disorders are one of the most common developmental disorders in children, with reported prev- alence rates of 3\%-20\% [1-3]. According to the Diagnostic and Statistical Manual of Mental Disorders-IV (DSM-IV), they are classified into speech and language disorders. Developmental language disorder is the most frequent

Received July 28, 2016; Accepted January 23, 2017

Corresponding author: Hyo In Kim

Department of Physical Medicine and Rehabilitation, National Health Insurance Service Ilsan Hospital, 100 Ilsan-ro, Ilsandong-gu, Goyang 10444, Korea. Tel: +82-31-900-0671, Fax:+82-31-900-0671, E-mail: in430@naver.com

ORCID: Jiyong Kim (http://orcid.org/0000-0003-4693-8400); Seong Woo Kim (http://orcid.org/0000-0002-1548-8147); Ha Ra Jeon (http://orcid. org/0000-0002-4234-8086); Mee Ryung Woo (http://orcid.org/0000-0003-1178-4659); Hyo In Kim (http://orcid.org/0000-0003-0640-5597).

(c) This is an open-access article distributed under the terms of the Creative Commons Attribution Non-Commercial License (http://creativecommons.org/ licenses/by-nc/4.0) which permits unrestricted noncommercial use, distribution, and reproduction in any medium, provided the original work is properly cited. Copyright (c) 2017 by Korean Academy of Rehabilitation Medicine 
communication disorder in children, with a prevalence of approximately $5.95 \%[4,5]$. However, speech disorders in children also have similar prevalence rate, and it was reported that $7.5 \%$ of children from age $3-11$ years require speech therapy due to articulation and phonological disorders [6].

Speech, i.e., the oral communication of language, is the culmination of complex coordination of respiratory, velopharyngeal, laryngeal, and articulatory movements. Speech disorders are conditions where the patient experiences difficulties in performing these coordinations, and they are classified as articulation and phonological, fluency, or voice disorders [1-3]. Although these disorders have varying organic etiologies, including structural, neurological, and auditory causes, the most common etiology is idiopathic [7]. Primary articulation disorder is defined as a disability in articulation without other speech or linguistic disabilities, and without a known cause.

Inaccurate pronunciation is a common complaint observed in children visiting the outpatient clinic for further evaluation. On comprehensive speech and language evaluation, many show dysfunction not only with articulation, but also in other areas of language development. Considering that the therapeutic effects and the prognosis vary considerably across a wide spectrum of developmental problems, children who have isolated articulation disorders, and those who have accompanying language problems, must be differentiated.

Therefore, this study aims to analyze speech and linguistic features in children with developmental articulation disorder, and to compare the characteristics between children with isolated articulation disorder and those with accompanying language delay.

\section{MATERIALS AND METHODS}

\section{Subjects}

Among the children aged 3-7 years who visited the outpatient clinic of the Department of Physical Medicine and Rehabilitation between February 2007 and June 2015 with the chief complaint of inaccurate pronunciation, 117 children diagnosed with significant developmental articulation dysfunction (AD) were enrolled for this study.

The exclusion criteria were as follows: (1) children with $\mathrm{AD}$ due to secondary causes, such as organic brain lesion, cerebral palsy, genetic syndromes, autism spectrum disorder or intellectual disability, (2) children with anatomical problems in articulatory structure such as cleft palate, (3) children with hearing impairment, and (4) children who were unable to undergo standardized articulation assessments because of severe language developmental delay. Standardized assessments, including physical and neurological examination, developmental \& cognitive assessment in all subjects, brain MRI, and hearing evaluation when required, were done to rule out $\mathrm{AD}$ caused by secondary causes.

\section{Methods}

Language ability was assessed using the Sequenced Language Scale for Infants (SELSI) or the Preschool Receptive-Expressive Language Scale (PRES), according to age and function. However, SELSI was also used for children aged $>3$ years whose language abilities were inadequate for PRES [8]. For the comprehensive speech and language assessment, receptive and expressive language quotients were defined as the percentage of receptive language age and expressive language age, both of which were divided by the chronological age of the patient. The criteria for developmental language delay was defined as the language age of the patient being below two standard deviations (SD) for SELSI, or their language age being delayed by at least 1 year compared to standard for PRES [810].

Assessment of Phonology and Articulation for Children (APAC) was used to assess articulation in the child. This test evaluates preschoolers aged 30-77 months for their articulatory ability. APAC obtains information on the number of normal consonants pronounced among a total of 70 consonants using responses to words, percentage of consonants correct (PCC), SD of each consonant, and pattern of articulatory error $[11,12]$. The criterion for articulation disorder is defined as being below 1 percentile of PCC when assessed with the number of normal consonants specific for the chronological age according to APAC. Based on the results of the comprehensive speech and language assessment, all subjects with articulation disorder were classified into two groups, depending on the presence of language delay. The AD group was defined as isolated articulation disorder, and the AD with language delay group was defined as $\mathrm{AD}$ overlapped with delayed language development. 
To evaluate whether the $\mathrm{AD}$ was due to delayed language development in the $\mathrm{AD}$ with language delay group, subgroup analysis was performed by adjusting the patients' expressive language age. After adjustment, the articulation function of children was reassessed to abnormal ( $\leq-2 \mathrm{SD}$ ) and borderline to normal (>-2SD) groups, based on the number of normal consonants.

\section{Statistical analyses}

SPSS ver. 22.0 (IBM, Armonk, NY, USA) was used for statistical analyses. Differences between the two groups in gender, expressive language quotient, and receptive language quotient were assessed using the t-test. PCC, the number of normal consonants between specific age groups, were assessed using the independent t-test. The $\chi^{2}$ test was used to analyze differences by age. The level of statistical significance was set at $\mathrm{p}<0.05$.

\section{RESULTS}

Of the 117 children, 55 were diagnosed as $\mathrm{AD}$ and 62 were diagnosed as $\mathrm{AD}$ with language delay. The male to female ratios were 1.6:1 in the $\mathrm{AD}$ group, and 2.6:1 in the $\mathrm{AD}$ with language delay group. However, the difference was not statistically significant. With regards to age, 36 children (30.8\%) were aged between 48-59 months, 28 (23.9\%) between $60-71$ months, 27 (23.1\%) were 36-47 months, and 26 (22.2\%) were $\geq 72$ months, in descending order of frequency. No statistical difference in the distribution of age was observed between the two groups.

The expressive and receptive language quotients were $89.64 \pm 13.40$ and $94.26 \pm 12.27$, respectively in the $\mathrm{AD}$ group, and $56.57 \pm 12.00$ and $61.83 \pm 13.35$, respectively in the $\mathrm{AD}$ with language delay group. Differences were statistically significant in the expressive and receptive language quotients between the two groups $(\mathrm{p}<0.05)$. Also, the expressive language quotients were lower than the receptive language quotients in both groups, but their differences were not significant (Table 1).

For the $\mathrm{AD}$ group and the $\mathrm{AD}$ with language delay group respectively, the mean PCC according to chronological age was $56.33 \pm 12.44$ and $55.39 \pm 11.22$ for age $36-47$ months, $57.52 \pm 12.78$ and $56.98 \pm 16.06$ for age $48-59$ months, $55.79 \pm 22.88$ and $68.63 \pm 15.42$ for age $60-71$ months, and $83.90 \pm 10.13$ and $74.62 \pm 15.33$ for age $\geq 72$ months. There were no statistically significant differences in PCC between the two groups according to age (Table 2).

In terms of the various consonants according to age, general order of decline in percentage of normal consonants was highest in nasal and plosive, followed by affricate, liquid, and fricative in all ages. This order was apparent in both $\mathrm{AD}$ and $\mathrm{AD}$ with language delay groups, for all age groups (Fig. 1).

When comparing the number of normal consonants

Table 1. General characteristics of children with developmental articulation disorder

\begin{tabular}{lcccc}
\hline & AD & $\begin{array}{c}\text { AD with } \\
\text { language } \\
\text { delay }\end{array}$ & p-value \\
\hline No of subject (\%) & $55(47)$ & $62(53)$ & \\
Sex & & & \\
$\quad$ Male & 34 & 45 & \\
Female & 21 & 17 & \\
Mean age (mo) & 67.63 & 56.73 & \\
Receptive quotient $^{\text {a) }}$ & $94.26 \pm 12.27$ & $61.83 \pm 13.35<0.001$ \\
\hline Expressive quotient $^{\text {a) }}$ & $89.64 \pm 13.40$ & $56.57 \pm 12.00$ & $<0.001$ \\
\hline
\end{tabular}

Values are presented as number (\%) or mean \pm SEM.

$\mathrm{AD}$, articulation dysfunction; SEM, standard error of the mean.

${ }^{a)} \mathrm{p}<0.001$ indicates values significantly different from those of $\mathrm{AD}$ and $\mathrm{AD}$ with language delay group.

Table 2. Percentage of consonants correct (\%) according to chronological age

\begin{tabular}{llcr}
\hline Age group & AD & AD with language delay & p-value \\
\hline $36-47$ mo & $56.33 \pm 12.44(18)$ & $55.39 \pm 11.22(9)$ & 0.419 \\
$48-59$ mo & $57.52 \pm 12.78(17)$ & $56.98 \pm 16.06(19)$ & 0.819 \\
$60-71$ mo & $55.79 \pm 22.88(11)$ & $68.63 \pm 15.42(17)$ & 0.225 \\
$\geq 72$ mo & $83.90 \pm 10.13(9)$ & $74.62 \pm 15.33(17)$ & 0.906 \\
\hline
\end{tabular}

Values are presented as mean \pm SEM and the parenthesis indicate a number of children.

$\mathrm{AD}$, articulation dysfunction.

$\mathrm{p}$-values are not significantly different from those of $\mathrm{AD}$ and $\mathrm{AD}$ with language delay group. 

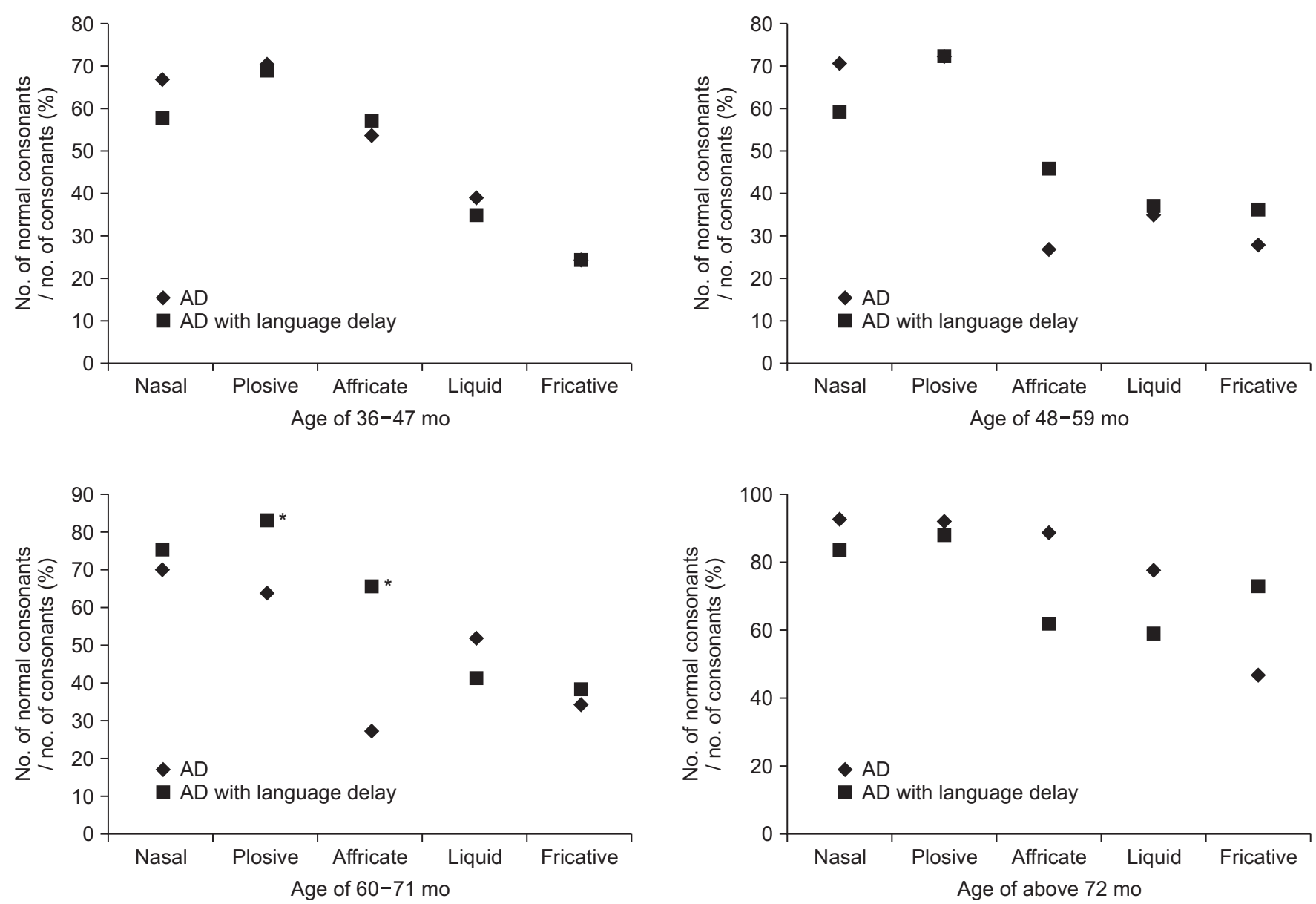

Fig. 1. The percentage of normal consonants per total number of each consonant, according to age and diagnosis. The acquisition of consonants was following the universal sequence of development in both groups. The percentage of normal plosive and affricate consonants per total number of each consonants was more in AD with language delay group than in $\mathrm{AD}$ group, in the age group of $60-71$ months ( $\mathrm{p}=0.025$ in plosive and $\mathrm{p}=0.012$ in affricate). $\mathrm{AD}$, articulation dysfunction. ${ }^{*} \mathrm{p}<0.05$ indicates values significantly difference from those of $\mathrm{AD}$ and $\mathrm{AD}$ with language delay group.

between the two groups, the percentage of both normal plosive and affricate consonants were higher in the $\mathrm{AD}$ with language delay group than in the $\mathrm{AD}$ group at the age range of $60-71$ months $(\mathrm{p}=0.025$ in plosive and $\mathrm{p}=$ 0.012 in affricate) (Fig. 1).

To evaluate whether the $\mathrm{AD}$ resulted from expressive language delay in the $\mathrm{AD}$ with language delay group, the subjects were adjusted to their expressive language age. In 62 children, 14 children (23\%) still showed abnormal articulation, and 33 children (53\%) were altered to borderline to normal articulation function. The remaining 15 children were categorized as unclassified, because their expressive language age was below 30 months of age, which was out of reference range for the APAC test (Table 3).
Table 3. Number of children corrected for expressive language age of number of normal consonants in the $\mathrm{AD}$ with language delay group

\begin{tabular}{|cccc}
\hline $\begin{array}{c}\text { Expressive } \\
\text { language } \\
\text { age group }\end{array}$ & Abnormal & $\begin{array}{c}\text { Borderline } \\
\text { \& Normal }\end{array}$ & Unclassified \\
\hline$<36$ mo & 1 & 20 & 15 \\
\hline $36-47$ mo & 8 & 8 & 0 \\
\hline $48-59$ mo & 3 & 4 & 0 \\
\hline $60-71$ mo & 0 & 1 & 0 \\
\hline$\geq 72$ mo & 2 & 0 & 0 \\
\hline Total & 14 & 33 & 15 \\
\hline
\end{tabular}

$\mathrm{AD}$, articulation dysfunction. 


\section{DISCUSSION}

High prevalence rates have been reported for communication disorders in children with various neurodevelopmental disorders [1-3]. Recently, there has been an increase in the number of children visiting the outpatient clinic with complaints of inaccurate pronunciation and delayed language development. One of the reasons could be the establishment of the referral system of the National Health Screening Program for Infants and Children, which started in November 2007 in Korea. According to the 2014 National Health Screening statistical yearbook, $3.2 \%$ of subjects were screened for further evaluation for delayed development through the Screening Program for Infants and Children, where many children screened were suspected of having communication problems.

According to the DSM-IV, communication disorders are classified into speech and language disorders. In the case of communication disorders, primary diagnosis is necessary to differentiate between speech and language domain [13]. Beitchman et al. [2,14] reported a long term follow-up study of 5-year-old children with communication disorders, have concomitant attention-deficit/hyperactivity and anxiety disorders. Patients showed persistent anxiety and antisocial personality disorders even after 14 years. Therefore, to prevent long-term complications, precise as well as early intervention is required. Furthermore, speech disorders are considered to be symptoms of an underlying language-learning problem, indicating an early intervention in articulation disorder (the most prevalent speech disorder) is very important [13]. In clinical practice, when speech intervention is provided to children with phonological and articulation disorder, the therapeutic effect was proven in expressive phonological and expressive vocabulary difficulties [15].

However, the distinction between speech and language disorders can be blurry in many cases [13]. Studies reported that children with developmental language disorder had accompanying articulation disorder, and children with inaccurate pronunciation had accompanying developmental language disorder [16]. Half of the preschoolers with articulation disorder also had a language disorder [17]. In our study, half the children with articulation disorder were diagnosed as AD overlapping with language delay. Thus, investigating children with any articulation problems should include not only the speech domain, but also the language domain. In our study, the male gender predisposition was noteworthy, and this tendency is in agreement with other reports, which indicate that speech and language problems are more common in males $[16,18]$. However, there was no apparent difference in the expression of AD with or without language delay.

According to the universal sequence of learning a phonological system, children usually follow the general rule of acquiring nasal and plosive articulation quicker than affricate, liquid, and fricative articulations [19]. This universal sequence was also observed in Korean children, who showed complete acquisition of nasal and plosive articulation at the age of 2 years, acquisition of affricate articulation by the age of 3 years, and acquisition of liquid and fricative articulation by the age of 5 years [20]. In our study, the acquisition of consonants according to the universal sequence was shown in all subjects. This result shows that the developmental milestones of Korean consonants are still preserved in children with articulation disorder, even in cases overlapping with language delay.

In children aged 60-71 months, plosive and affricate articulation function were better in $\mathrm{AD}$ than $\mathrm{AD}$ with language delay group. These distinguishing features appeared in specific consonants and specific age groups, thereby making it difficult to generalize. To characterize detailed speech features in Korean children, more research is required regarding articulation disorders.

The authors had pondered if articulation development is directly related to language development in $\mathrm{AD}$ overlapping with language delay. Hence, the presence of $\mathrm{AD}$ was reassessed after adjustment with expressive language level. Half the children demonstrated appropriate articulatory function after adjustment, indicating that the therapeutic goal for these children should preferably focus on the improvement of expressive language development instead of focusing on articulation alone.

Many reports have been published regarding articulation disorder and its assessment, and therapies for children with articulation disorder are already well formulated [21,22]. However, there are only a few studies on articulation disorder overlapping with language delay; therefore, its assessment and prognosis remains unclear. We reported on the speech and linguistic features of Korean children with developmental articulation disorder, and showed some heterogeneity of this group, and simi- 
larity and differences between $\mathrm{AD}$ and $\mathrm{AD}$ with language delay groups in this study.

This study has some limitations. Firstly, our study was conducted at one institute. Secondly, the subjects were evaluated cross-sectionally during developmental period, and could not be followed up longitudinally, making it difficult to illustrate the natural course of articulation disorder with or without overlap with language delay. Thirdly, children who could not undergo the standardized articulation assessment because of severe expressive language delay even in the presence of $\mathrm{AD}$, were excluded.

In conclusion, the present study showed that children with articulation disorder have heterogeneous phenotypes of speech and language profiles. About half the children with $\mathrm{AD}$ have developmental language problems as well. All children showed a similar pattern of consonants acquisition, but the articulation of plosive and affricate consonants were better in children who overlapped with language delay.

Also, in the current study, for children with AD with overlapping problem of language delay, half the cases reverted to appropriate articulation function if adjusted with expressive language age.

Therefore, comprehensive speech and language assessment need to be considered, and the results should be interpreted carefully in children with inaccurate pronunciation for exact diagnosis and proper treatment planning.

\section{CONFLICT OF INTEREST}

No potential conflict of interest relevant to this article was reported.

\section{REFERENCES}

1. Stevenson J, Richman N. The prevalence of language delay in a population of three-year-old children and its association with general retardation. Dev Med Child Neurol 1976;18:431-41.

2. Beitchman JH, Nair R, Clegg M, Patel PG, Ferguson B, Pressman E, et al. Prevalence of speech and language disorders in 5-year-old kindergarten children in the Ottawa-Carleton region. J Speech Hear Disord 1986; 51:98-110.

3. Tomblin JB, Records NL, Buckwalter P, Zhang X, Smith
E, O'Brien M. Prevalence of specific language impairment in kindergarten children. J Speech Lang Hear Res 1997;40:1245-60.

4. Coplan J, Gleason JR. Unclear speech: recognition and significance of unintelligible speech in preschool children. Pediatrics 1988;82(3 Pt 2):447-52.

5. Law J, Boyle J, Harris F, Harkness A, Nye C. Screening for speech and language delay: a systematic review of the literature. Health Technol Assess 1998;2:1-184.

6. Shriberg LD, Kwiatkowski J. Developmental phonological disorders. I. A clinical profile. J Speech Hear Res 1994;37:1100-26.

7. Ruscello DM. Treating articulation and phonological disorders in children. 3rd ed. St. Louis, MO: Mosby; 2008.

8. Kim SW, Jeon HR, Park EJ, Kim HI, Jung DW, Woo MR. The usefulness of M-B CDI-K short form as screening test in children with language developmental delay. Ann Rehabil Med 2014;38:376-80.

9. Kim YT, Kim KH, Yoon HR, Kim WS. Sequenced Language Scale for Infants (SELSI). Seoul: Special Education Publication Co.; 2003.

10. Kim YT, Sung TJ, Lee YK. Preschool Receptive-Expressive Language Scale (PRES). Seoul: Seoul Welfare Center for People with Disabilities; 2003.

11. Yoo HJ, Kim HH, Kim WS, Shin JC. Articulation ability and phonological process in multicultural family children. Speech Sci 2008:15;133-44.

12. Kim MJ, Pae SY, Park CI. Assessment of Phonology and Articulation for Children (APAC). Seoul: Human Brain Research \& Consulting; 2005.

13. Sharp HM, Hillenbrand K. Speech and language development and disorders in children. Pediatr Clin North Am 2008;55:1159-73.

14. Beitchman JH, Wilson B, Johnson CJ, Atkinson L, Young A, Adlaf E, et al. Fourteen-year follow-up of speech/language-impaired and control children: psychiatric outcome. J Am Acad Child Adolesc Psychiatry 2001;40:75-82.

15. Law J, Garrett Z, Nye C. Speech and language therapy interventions for children with primary speech and language delay or disorder. Cochrane Database Syst Rev 2003:CD004110.

16. Kwon JY, Kim JS, Woo AM, Kim HJ, Chung ME, Kim HS, et al. Diagnosis of speech disorder and language developmental delay in Korean preschoolers. J Korean 
Acad Rehabil Med 2006;30:309-14.

17. Tyler AA, Lewis KE, Haskill A, Tolbert LC. Efficacy and cross-domain effects of a morphosyntax and a phonology intervention. Lang Speech Hear Serv Sch 2002; 33:52-66.

18. Kim SW, Shin JB, You S, Yang EJ, Lee SK, Chung HJ, et al. Diagnosis and clinical features of children with language delay. J Korean Acad Rehabil Med 2005;29:58490.

19. Jakobson R. Child language, aphasia and phonologi- cal universals. The Hague: Mouton Publisher; 1968.

20. Kim YT. The percentage of correct consonants in preschoolers used by Picture Articulation Test. Korean J Commun Disord 1996;1:7-33.

21. Park SH, Kang AY, Kang MG, Lee SK. Research trends of articulation and phonological disorder in Korea. J Speech Hear Disord 2012;21:1-18.

22. Kim YT. Evaluation and treatment for the children with articulation-phonology disorders. J Korean Assoc Sci Educ 2001;9:63-83. 